\title{
Viscoelastic creep behavior of surface- and inner-layers of sugi boxed-heart timber under various temperatures
}

\author{
Andi Hermawan ${ }^{1 *}$ (D) and Noboru Fujimoto ${ }^{2}$
}

\begin{abstract}
This study was conducted to investigate the rheological behavior of sugi boxed-heart timber under constant moisture content (MC) using a cantilever creep test. The focus of the study was the effect of temperature on viscoelastic creep behavior of surface- and inner-layer specimens of the timber. The specimens with dimensions of $75 \mathrm{~mm}$ in length, $25 \mathrm{~mm}$ wide, and $3 \mathrm{~mm}$ thick were prepared. A cantilever creep test with an effective span of $40 \mathrm{~mm}$ was conducted under a constant temperature of $20,65,80$, and $95^{\circ} \mathrm{C}$. The equilibrium moisture content (EMC) of the specimens was set to around $12 \%$ at each temperature. A load representing $20 \%$ of rupture load of the specimens at each temperature was applied to their free-end and strain gauges were bonded at the fourth span $(10 \mathrm{~mm})$ on the upper and bottom surfaces of the specimens. Loading and unloading duration were set for 300 and 180 min, respectively, and a four-element Burgers model was used to model the creep behavior of the timber. It was found that temperature had significant effects on the creep properties of the timber. The surface strain and creep compliance of the surface- and inner-layer specimens tended to increase as the temperature increased. Creep compliance of the surfacelayer specimen was higher than that of the inner-layer specimen at each temperature. Fitting the experimental data with the Burgers model used in this study shows good agreement and it was found that elastic (instantaneous) and viscoelastic (delayed) creep compliance of all the specimens tended to increase as the temperature increased. On the other hand, the viscosity of the dashpot element of both the Maxwell and the Kelvin unit tended to decrease as the temperature increased. Although different in magnitude, the creep-recovery compliance parameters had the same tendency as the creep compliance parameters.
\end{abstract}

Keywords: Sugi, Boxed-heart timber, Viscoelastic creep, Burgers model, Parameter identification

\section{Introduction}

Sugi (Cryptomeria japonica) is the most important commercial wood species in Japan. Generally, thinned sugi trees are sawn into boxed-heart timber and used for structural purposes in Japanese traditional post-andbeam construction. Timber for structural purposes should be dried to a moisture content $(\mathrm{MC})$ that is lower than $20 \%$ [1] to prevent future dimensional changes because of moisture fluctuation. However, it is very difficult to achieve high-quality dried boxed-heart timber

\footnotetext{
*Correspondence: andi@umk.edu.my

${ }^{1}$ Forest Resource Technology, Faculty of Bioengineering and Technology, Universiti Malaysia Kelantan, Kampus Jeli, 17600 Jeli, Kelantan, Malaysia Full list of author information is available at the end of the article
}

with fewer surface and internal checks because checks often occur during the drying of the timber due to obvious anisotropic shrinkage.

In Japan, various pre-treatments and drying methods have been developed to achieve higher quality dried boxed-heart timber as well as to reduce its drying time [2-4]. Recently, high-temperature and low-humidity (HT-LH) pre-treatment has been developed and widely used in Japan to prevent the occurrence of surface checks in the timber [5-8]. During HT-LH pre-treatment, green boxed-heart timber was exposed to dry heat at a temperature of more than $100{ }^{\circ} \mathrm{C}$. Under these circumstances, it was thought that thermal softening would occur on the surface-layer of the timber and contribute to the effective relaxation of tensile stress. Thus, large drying set formed 
at the surface-layer of the timber resulted in the occurrence of fewer surface checks. On the other hand, it has also been reported that excessive temperature and time as pre-treatment conditions would have a negative effect on the timber in terms of internal check occurrence [7]. However, an accurate understanding of the mechanism of HT-LH pre-treatment that prevents the occurrence of checks in the timber is still lacking.

Very little research has been conducted to provide a theoretical description of the HT-LH pre-treatment mechanism in terms of the prevention of surface checks in boxed-heart timber. In Japan, more than 3 decades ago a rheological approach was proposed to clarify the effect of temperature on the development of checks during the drying of timber. For this purpose, experimental research was most commonly based on a tensile creep test using thin samples. Hisada [9] investigated the creep and set behavior of makanba and hinoki timber. A tensile creep test was conducted perpendicularly to the grain and the effects of temperature on the creep behavior of the timber were investigated. An equation expressing a relationship between temperature and the creep compliance of the timber was developed and an index of critical initial check occurrence was then proposed. In addition, Fujimoto et al. [10] investigated the tensile creep behavior of the surface-layer of sugi boxed-heart timber and the compressive creep behavior of the inner-layer of this timber under various temperatures. It was reported that temperature had a significant effect on creep and residual strain under constant MC. Although the tensile and compressive creep tests are closely analogous to the mechanical behavior of the timber during drying, however, in this experiment, tensile and compressive creep tests were conducted separately using different sample sizes and shapes. In most cases, the creep behavior of the timber was found to vary in terms of tension and compression load. On the other hand, Moutee et al. [11] have developed a cantilever creep test to model the creep behavior of wood during drying. This test is simple and much more closely analogous to the mechanical behavior of wood during drying because when a cantilever beam is subjected to a load at its free-end, tension and compression stress occur, respectively, on its upper and bottom faces at the same time.

This study was conducted to investigate rheological behavior of sugi boxed-heart timber under constant MC using a cantilever creep test as part of a project that was focused on investigation of checks occurrence in some Japanese softwood during drying. We believed that the responses of the timber, especially at its surfaceand inner-layers to temperature and $\mathrm{MC}$ change under applied stress contributed greatly to the occurrence of checks in the timber. In this study, therefore, the effects of temperature on viscoelastic creep behavior of the surface- and inner-layers of the timber were investigated. A four-element Burgers model was used to model the creep behavior of the timbers under various temperatures. Creep and creep-recovery parameters were then obtained by fitting experimental data with the rheological model used in this study.

\section{Materials and methods Materials}

Sugi boxed-heart timber obtained from a local saw mill in Fukuoka Prefecture, Japan was used as raw materials in this study. The dimension of the timber was $133 \times 133 \times 3000 \mathrm{~mm}$ with average initial MC and air-dry density was $47.1 \%$ and $0.43 \mathrm{~g} / \mathrm{cm}^{3}$, respectively.

\section{Methods}

\section{Specimen preparation}

Sugi boxed-heart timbers were cut to a length of $500 \mathrm{~mm}$ by cross-sectional cutting producing four $500-\mathrm{mm}$ length timbers used for rupture load test and creep test under temperature of $20,65,80$ and $95{ }^{\circ} \mathrm{C}$. The $500-\mathrm{mm}$ length timbers were cut parallel to the grain at the surface- and inner-layer to produce flat sawn and quarter sawn boards, respectively. The boards were then planed to a thickness of $3 \mathrm{~mm}$, producing boards with a dimension of $500 \mathrm{~mm}$ in length, $133 \mathrm{~mm}$ wide, and $3 \mathrm{~mm}$ thick. After being conditioned in the conditioning room at a temperature of $20^{\circ} \mathrm{C}$ to an equilibrium moisture content (EMC) of 12\%, the boards were cut parallel to the grain to produce boards with a dimension of $500 \mathrm{~mm}$ in length, $75 \mathrm{~mm}$ wide, and $3 \mathrm{~mm}$ thick. Finally, the boards were cut perpendicularly to the grain to a length of $25 \mathrm{~mm}$, producing test specimens with dimensions of $75 \mathrm{~mm}$ in length, $25 \mathrm{~mm}$ wide, and $3 \mathrm{~mm}$ thick. The average airdry density was $0.44 \mathrm{~g} / \mathrm{cm}^{3}$ for both surface- and innerlayer specimens. Cantilever specimens with an effective span of $40 \mathrm{~mm}$ were used in this study. We particularly focused on mechanical and rheological responses of surface- and inner-layers of the timber where initial checks usually occur during drying. Generally, surface checks occur initially at the center of cathedral or crown grain of the surface layer, while internal checks occur initially around the pith of the timber. Therefore, the fixed-end position of the cantilever for the surface-layer specimens was set at the center of cathedral or crown grain of the flat sawn board. On the other hand, the fixed-end of the inner-layer specimens of the timber was set at a position a little away from the pith. Figure 1 shows the specimen preparation and the cantilever fixed-end position of each specimen. 


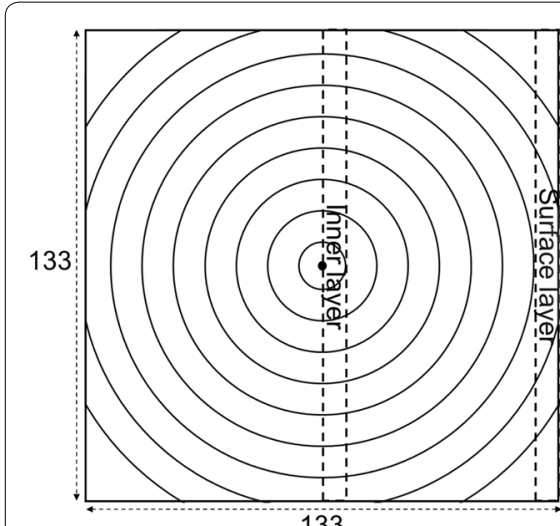

133

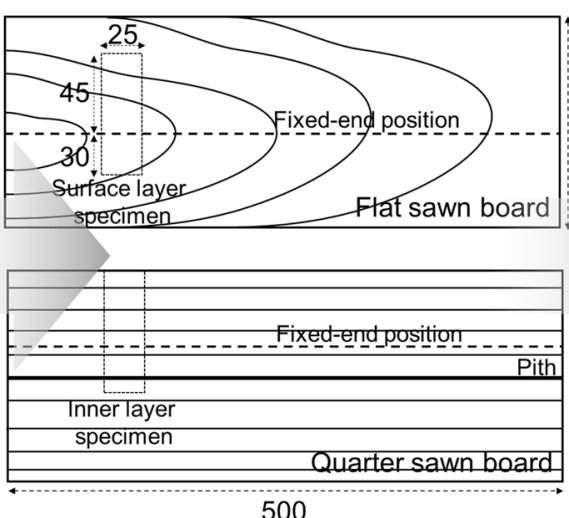

500

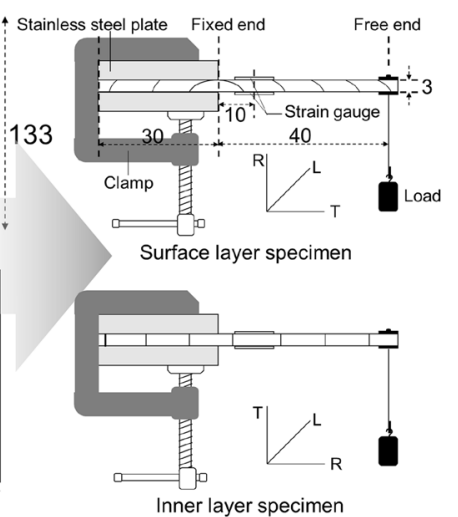

Unit: $\mathrm{mm}$

Fig. 1 Schematic diagram showing preparation of the specimens and the cantilever fixed-end position

\section{Rupture load and creep tests}

Rupture load and creep tests were conducted in a laboratory temperature and humidity chamber under a constant temperature of $20,65,80$, and $95^{\circ} \mathrm{C}$. The EMC of the specimen at each temperature was set to around $12 \%$ by adjusting the relative humidity $(\mathrm{RH})$ inside the chamber. Table 1 shows the test conditions and applied load in creep test used in this study. In rupture load test, a static load was hung at the free-end of the cantilever using a jig connecting the static load to a load cell using a wire. The load cell was then connected using a wire running through a pulley to the stepping motor so that the load was in a static equilibrium condition, as shown in Fig. 2. The load was applied and increased progressively until rupture occurred at the fixed-end of the cantilever by moving the stepping motor forward at a speed of $2 \mathrm{~mm} / \mathrm{min}$. Load increment data were recorded using a data logger at intervals of $1 \mathrm{~s}$. In case of creep test, a load representing $20 \%$ of the ultimate rupture load at each temperature was applied at the free-end of the cantilever under constant EMC. Strain gauges were bonded at the fourth span $(10 \mathrm{~mm})$ on the upper (tension) and bottom (compression) surfaces of the specimen. The load was applied using the same principle as that used in the rupture load test. A wire with a static load at the end was connected to the stepping motor through a pulley. Loading was conducted by moving the stepping motor forward until the static load hung on a jig at the free-end of the cantilever and vice versa for unloading. Loading duration was set for $300 \mathrm{~min}$ and recovery duration was set for $180 \mathrm{~min}$ after unloading. Surface strains were recorded using the data logger at intervals of $1 \mathrm{~s}$. The specimen was conditioned at each test condition for more than 6 and $12 \mathrm{~h}$ prior to the rupture test and the creep test, respectively. In addition, free-end deflection was measured only for the rupture load test and the creep test under temperature of $20^{\circ} \mathrm{C}$ using laser displacement sensor.

\section{Rheological model}

Many rheological models have been proposed to describe viscoelastic creep behavior of wood. Hanhijärvi and Mackenzie-Helnwein [12] used a series of Kelvin elements to describe creep behavior of wood under constant MC. Zhan et al. [13] used simple equations to predict elastic strain and viscoelastic creep strain of Larch timber based on changes in longitudinal, radial and tangential directions of the sample measured using a slicing method. Cai et al. [14] developed a creep model based on modified power law functions and the results indicate that these functions provide the best fit to both primary and secondary experimental viscoelastic creep data. In this

Table 1 Test conditions and applied load in creep test

\begin{tabular}{|c|c|c|c|c|c|}
\hline \multirow[t]{2}{*}{ Temperature $\left({ }^{\circ} \mathrm{C}\right)$} & \multirow[t]{2}{*}{ RH (\%) } & \multirow[t]{2}{*}{ EMC (\%) } & \multicolumn{2}{|c|}{ Applied load in creep test $(N)$} & \multirow[t]{2}{*}{ Replication } \\
\hline & & & Surface-layer & Inner-layer & \\
\hline 20 & 66 & 12.2 & 1.86 & 2.15 & \multirow{4}{*}{$\begin{array}{l}6 \text { (rupture load test) } \\
5 \text { (creep test) }\end{array}$} \\
\hline 65 & 78 & 12.3 & 1.31 & 2.02 & \\
\hline 80 & 80 & 11.6 & 1.26 & 1.79 & \\
\hline 95 & 86 & 12.0 & 0.78 & 1.54 & \\
\hline
\end{tabular}





Fig. 2 Schematic diagram of the tests conducted in this study. a Rupture load test; $\mathbf{b}$ creep test

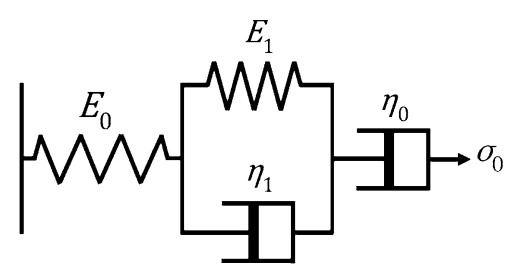

Fig. 3 Schematic diagram of the four-element Burgers model

study, however, the four-element Burgers model, which consists of one Maxwell and one Kelvin unit connected in a series used to model viscoelastic creep behavior of the timber. The four-element Burgers model, including instantaneous, viscoelastic and viscous deformation resulting from the Maxwell spring, the Kelvin unit, and the Maxwell dashpot, respectively, is presented in Fig. 3. The four-element Burgers model can be expressed by the following equations:

$$
\varepsilon(t)=\left[\frac{1}{E_{0}}+\frac{1}{E_{1}}\left(1-\mathrm{e}^{-t / \tau_{1}}\right)+\frac{1}{\eta_{0}} t\right] \sigma_{0}, \quad \tau_{1}=\frac{\eta_{1}}{E_{1}}
$$

$$
\varepsilon(t)=\frac{\varepsilon^{+}-\varepsilon^{-}}{2}
$$

and the results were expressed by compliance function $J(t)$ and can be calculated as follows:

$$
J(t)=\frac{\varepsilon(t)}{\sigma_{0}}
$$

where $\varepsilon(t)$ is creep strain; $\varepsilon^{+}$and $\varepsilon^{-}$are strain on the upper (tension) and bottom (compression) surfaces of the specimen, respectively; $E_{0}$ and $E_{1}$ are instantaneous and delayed elastic modulus, respectively; $\tau_{1}$ is retardation time to produce $63.21 \%$ (or $1-1 / e$ ) of its total deformation; $\sigma_{0}$ is applied stress; $t$ is time; $\eta_{0}$ and $\eta_{1}$ are viscosities of the dashpot in the Maxwell and Kelvin units, respectively; $J(t)$ is creep compliance.

From Eqs. (1) and (3), $J(t)$ can be expressed as:

$$
J(t)=J_{0}+J_{1}\left(1-e^{-t / \tau_{1}}\right)+\frac{1}{\eta_{0}} t, \quad J_{i}=\frac{1}{E_{i}}
$$

where $J_{0}$ and $J_{1}$ are instantaneous and delayed elastic compliance, respectively.

In this study, $\varepsilon(t)$ was stated as: 
Table 2 Average MOR, MOE, and MC of the specimen before and after rupture load test

\begin{tabular}{|c|c|c|c|c|c|c|c|c|}
\hline \multirow[t]{3}{*}{ Temperature $\left({ }^{\circ} \mathrm{C}\right)$} & \multicolumn{4}{|c|}{ Surface-layer } & \multicolumn{4}{|l|}{ Inner-layer } \\
\hline & \multirow[t]{2}{*}{ MOR (MPa) } & \multirow[t]{2}{*}{ MOE (GPa) } & \multicolumn{2}{|l|}{ MC (\%) } & \multirow[t]{2}{*}{ MOR (MPa) } & \multirow[t]{2}{*}{ MOE (GPa) } & \multicolumn{2}{|l|}{ MC (\%) } \\
\hline & & & Before & After & & & Before & After \\
\hline 20 & $9.76(1.42)$ & $0.47(0.10)$ & $11.9(0.7)$ & $13.6(0.5)$ & $13.28(1.11)$ & $0.95(0.21)$ & $10.8(1.2)$ & $12.9(0.4)$ \\
\hline 65 & $7.53(1.43)$ & - & $10.5(1.2)$ & $13.5(2.0)$ & $12.53(2.45)$ & - & $10.7(1.4)$ & $12.5(0.8)$ \\
\hline 80 & 7.48 (1.39) & - & $10.0(0.4)$ & $10.7(0.4)$ & $11.36(2.13)$ & - & $9.6(0.4)$ & $10.2(0.3)$ \\
\hline 95 & $4.55(1.01)$ & - & $10.3(0.8)$ & $9.9(0.8)$ & $9.14(1.80)$ & - & $9.5(0.9)$ & $9.4(0.9)$ \\
\hline
\end{tabular}

Note: Number in parentheses indicates standard deviation

Hyphen indicates that no measurement was conducted

When the constant load was removed at time $t_{r}$, the specimen started to recover, which is the reverse of creep. According to Boltzmann's superposition principle, creeprecovery compliance at $t>t_{r}$ can be expressed as follows:

$$
J_{r}(t)=J\left(t_{r}\right)-J_{0}-J_{1}\left[1-e\left(-\frac{t-t_{r}}{\tau_{1}}\right)\right]
$$

where $J_{r}(t)$ is creep-recovery compliance and $t_{r}$ is unloading time.

\section{Results and discussion}

\section{Rupture load}

The modulus of rupture (MOR), the modulus of elasticity (MOE), and the MC of surface- and inner-layer



Fig. 4 Surface strain and free-end deflection of sugi boxed-heart timber at each temperature. a Surface-layer specimen; $\mathbf{b}$ inner-layer specimen specimens of the timber are presented in Table 2. As expected, the specimens exposed at temperature of $20^{\circ} \mathrm{C}$ had the highest MOR. Table 2 shows that the MOR of all the specimens tended to decrease as the temperature increased. It is well known that MOR is sensitive to heat, and much research has been reported in which the MOR of the timber decreased when exposed to a higher temperature condition [15-18]. It was found also that both MOR and MOE of the surface-layer specimen were lower than those of the inner-layer specimen. This is probably due to the orientation of ray tissues to the length of the specimen and applied load direction. In inner-layer
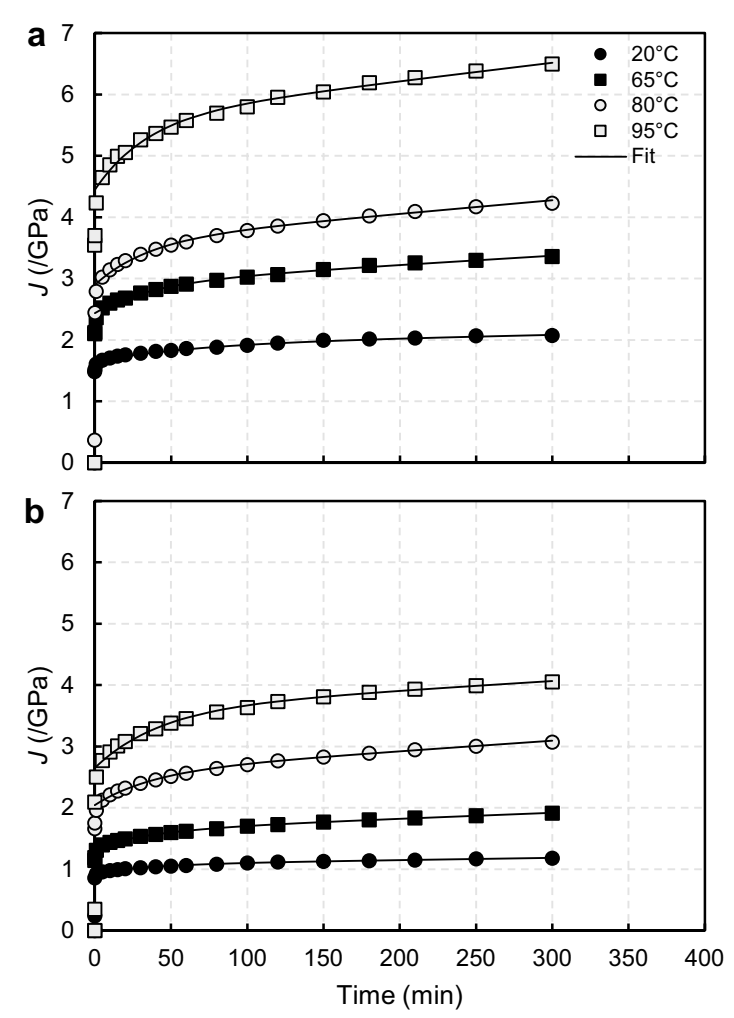

Fig. 5 Creep compliance of sugi boxed-heart timber at each temperature. a Surface-layer specimen; $\mathbf{b}$ inner-layer specimens 
specimen, the ray tissues oriented parallel and perpendicular to the length of the specimen and applied load direction, respectively, give reinforcement effects to the specimen. Contrasting to the inner-layer specimen, the ray tissue of surface-layer specimen oriented perpendicular and parallel to the length of the specimen and applied load, respectively, causing upper (tension) surface of the specimen prone to cleavage when load was applied at its free-end.

\section{Surface strain and free-end deflection}

The surface strain and free-end deflection of the surface- and inner-layer specimens of the timber at each temperature are presented in Fig. 4. After loading, all the specimens exhibited elastic (instantaneous) and viscoelastic (delayed) strain and the strain was found to increase rapidly at the first $30 \mathrm{~min}$ and then become slower. Figure 4 shows that the elastic and viscoelastic strain of the specimens tended to increase as the temperature increased. When the load was removed, the strain started to recover and only the elastic deformation component recovered immediately. The viscoelastic deformation strain is recovered gradually and incompletely. Figure 4 clearly shows that a significant residual strain still remained (permanent plastic deformation), especially for the specimens exposed at a higher temperature. In addition, Fig. 4 shows the free-end deflection of the surface-layer specimen of the timber was larger than that of the inner-layer specimen. This is because the MOE of the inner-layer specimen was larger than that of surfacelayer specimen as shown in Table 2.

\section{Creep properties}

Figure 5 shows typical creep compliance of surface- and inner-layer specimens of sugi boxed-heart timber at each temperature. Figure 5 confirmed that temperature had a significant effect on creep compliance of the specimens. As can be seen from the figure, the creep compliance of the specimens tended to increase as the temperature
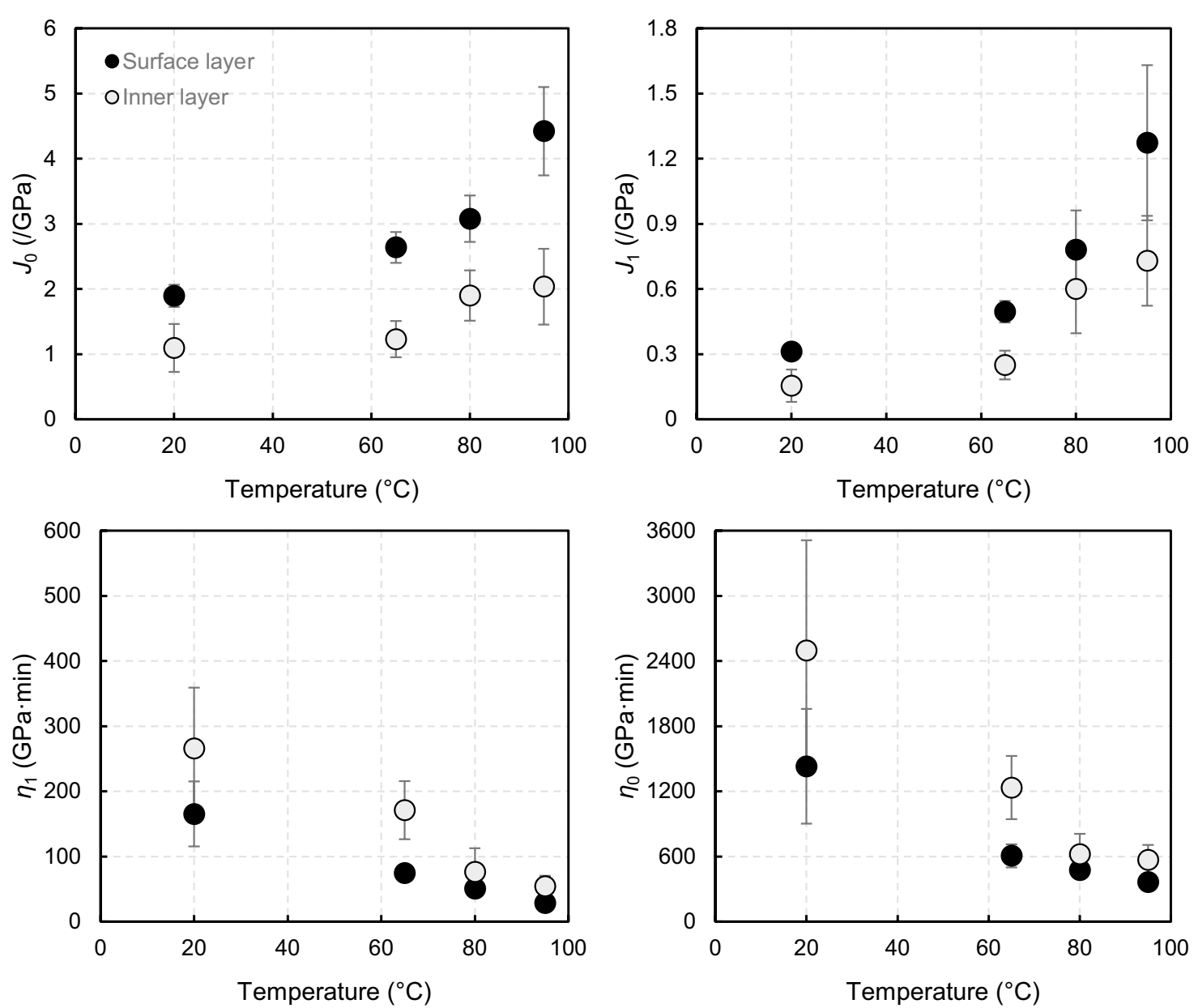

Fig. 6 Creep parameters of surface- and inner-layers of sugi boxed-heart timber at each temperature. The error bar indicates standard deviation 
increased. This is because thermal softening occurs hence the mobility of the macromolecules of the specimens increases which leads to a higher deformation of the specimen due to reduction of its elasticity. It is also clear from the results that at each temperature, the surface-layer specimen has higher creep compliance than that of the inner-layer specimen. Fitting the experimental data with the Burgers model used in this study shows good agreement, as can be seen in Fig. 5 (solid line). Therefore, the model parameters obtained in this study were applicable for the identification of the creep behavior of timber.

Figure 6 shows the creep compliance parameters of the surface- and inner-layer specimens of sugi boxed-heart timber at each temperature. The first elastic (instantaneous) compliance $\left(J_{0}\right)$ arises from the spring element of the Maxwell unit, and later time-dependent deformation comes from the spring $\left(J_{1}\right)$ and dashpot $\left(\eta_{1}\right)$ elements of the Kelvin unit and is followed by viscous flow from the dashpot $\left(\eta_{0}\right)$ element of the Maxwell unit. From Fig. 6 , it can be seen that for all the specimens, $J_{0}$ and $J_{1}$ tended to increase as the temperature increased. The $J_{0}$ and $J_{1}$ of the surface-layer specimen were 1.90 and 0.31 , 2.64 and $0.50,3.08$ and 0.78 , and 4.42 and $1.27 / \mathrm{GPa}$ at temperature of $20,65,80$ and $95{ }^{\circ} \mathrm{C}$, respectively. While, the $J_{0}$ and $J_{1}$ of the inner-layer specimen were 1.10 and $0.16,1.23$ and $0.25,1.90$ and 0.60 , and 2.04 and $0.73 /$ $\mathrm{GPa}$ at temperature of $20,65,80$ and $95{ }^{\circ} \mathrm{C}$, respectively. According to Eq. (4), $J_{0}$ and $J_{1}$ are the inverse of $E_{0}$ and $E_{1}$, respectively. This indicated that the elasticity of all the specimens decreased as the temperature increased due to thermal softening. In addition, $J_{0}$ and $J_{1}$ of the surfacelayer specimens were higher than those of the inner-layer specimens. This behavior implied that as the temperature increased, the inner-layer specimens retained their elasticity better than the surface-layer specimens did.

Figure 6 also shows that for all the specimens, $\eta_{0}$ and $\eta_{1}$ tended to decrease as the temperature increased. It is known that $\eta_{0}$ represents irrecoverable creep due to permanent plastic deformation of the specimen, while $\eta_{1}$ relates to viscosity of the Kelvin unit, and, as expressed in Eq. (1), the ratio between $\eta_{1}$ and $E_{1}$ is defined as retardation time $\left(\tau_{1}\right)$. The results in Fig. 6 indicated that as the temperature increased, higher flow due to thermal softening occurred in the dashpot elements and, accordingly, retardation time decreased and permanent plastic deformation of the specimen increased. The $\eta_{0}$ and $\eta_{1}$ of the surface-layer specimen were lower than those of the inner-layer specimens. The $\eta_{0}$ and $\eta_{1}$ of the surface-layer specimen were 1430.28 and 165.36, 606.49 and 74.45, 476.07 and 50.43 , and 363.41 and $28.47 \mathrm{GPa}$ min at temperature of $20,65,80$ and $95{ }^{\circ} \mathrm{C}$, respectively. While, the $\eta_{0}$ and $\eta_{1}$ of the inner-layer specimen were 2497.34 and
265.84, 1234.52 and $171.12,619.94$ and 76.48 , and 568.73 and $54.24 \mathrm{GPa}$ min at temperature of $20,65,80$, and $95{ }^{\circ} \mathrm{C}$, respectively. This result shows that the surfacelayer specimens have higher permanent plastic deformation than the inner-layer specimens.

\section{Creep-recovery properties}

Figure 7 shows typical creep-recovery compliance of surface- and inner-layer specimens of sugi boxed-heart timber at each temperature. Although the expression for $J_{r}$ (t) obtained in Eq. (5) does not contain $\eta_{0}$ which represent irrecoverable creep, the fact that the creep-recovery compliance is not fully recovered following unloading indicates the presence of permanent plastic deformation in all the specimens even at a temperature of $20^{\circ} \mathrm{C}$. The un-recovered compliances at the end of $3 \mathrm{~h}$ recovery showed an increase as the temperature increased.

Figure 8 shows the creep-recovery compliance parameters of the surface- and inner-layer specimens of sugi boxed-heart timber at each temperature. Although different in magnitude, the creep-recovery compliance parameters had the same tendency as the creep compliance



Fig. 7 Creep-recovery compliance of sugi boxed-heart timber at each temperature. a Surface-layer specimen; $\boldsymbol{b}$ inner-layer specimens 

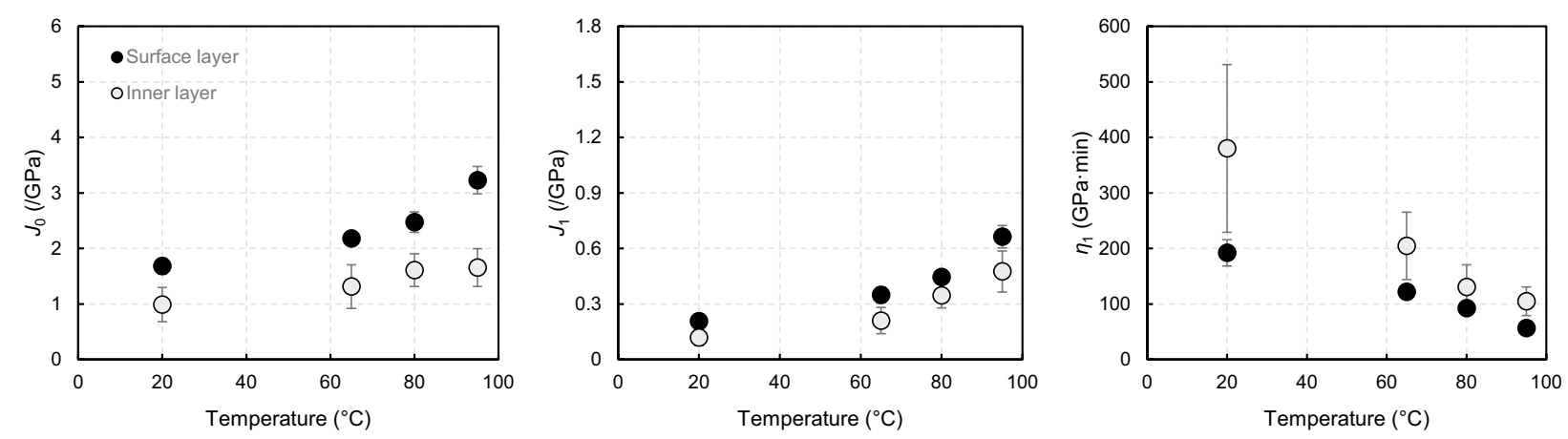

Fig. 8 Creep-recovery parameters of surface- and inner-layers of sugi boxed-heart timber at each temperature. The error bar indicates standard deviation

parameters described above. Figure 8 shows that for all the specimens, $J_{0}$ and $J_{1}$ tended to increase as the temperature increased. Figure 8 also shows that $J_{0}$ and $J_{1}$ of surface-layer specimen were higher than those of innerlayer specimens. The $J_{0}$ and $J_{1}$ of the surface-layer specimen were 1.68 and $0.21,2.18$ and $0.35,2.47$ and 0.45 , and 3.23 and $0.66 / \mathrm{GPa}$ at temperature of $20,65,80$ and $95^{\circ} \mathrm{C}$, respectively. While, the $J_{0}$ and $J_{1}$ of the inner-layer specimen were 0.99 and $0.12,1.31$ and $0.21,1.61$ and 0.35 , and 1.66 and $0.48 / \mathrm{GPa}$ at temperature of $20,65,80$ and $95^{\circ} \mathrm{C}$, respectively.

On the other hand, Fig. 8 shows that $\eta_{1}$ tended to decrease as temperature increased. The $\eta_{1}$ of the surfacelayer specimens was lower than that of the inner-layer specimens. The $\eta_{1}$ of the surface-layer specimens was $192.06,121.73,92.51$ and $56.58 \mathrm{GPa}$ min at temperature of $20,65,80$ and $95{ }^{\circ} \mathrm{C}$, respectively. While, the $\eta_{1}$ of the inner-layer specimens was 380.13, 204.73, 130.66 and 104.97 GPa min at temperature of $20,65,80$ and $95{ }^{\circ} \mathrm{C}$, respectively. This finding confirmed that permanent deformation was present, and greater at a higher temperature and in the surface-layer than in the inner-layer of sugi boxed-heart timber.

\section{Conclusions}

This study presents viscoelastic creep behavior of surface- and inner-layers of sugi boxed-heart timber under constant $\mathrm{MC}$ using a cantilever creep test. The results show that temperature had significant effects on the creep properties of sugi boxed-heart timber. The surface strain and creep compliance of the surface- and innerlayer specimens tended to increase as the temperature increased. Creep compliance of the surface-layer specimen was higher than that of the inner-layer specimen at each temperature. Fitting the experimental data with the Burgers model used in this study shows good agreement and it was found that elastic (instantaneous) and viscoelastic (delayed) creep compliance of all the specimens tended to increase as the temperature increased. On the other hand, the viscosity of the dashpot element of both the Maxwell and the Kelvin unit tended to decrease as the temperature increased. Although different in magnitude, the creep-recovery compliance parameters had the same tendency as the creep compliance parameters. In addition, further study regarding the effect of moisture fluctuation on rheological behavior of the timber is needed to describe the mechanism of stress development induced by hygrothermal conditions during drying.

\section{Abbreviations}

MC: Moisture content; EMC: Equilibrium moisture content; HT-LH: High temperature and low humidity; RH: Relative humidity; MOR: Modulus of rupture; MOE: Modulus of elasticity.

\section{Acknowledgements}

The authors would like to express their gratitude to the Japan Society for the Promotion of Science (JSPS) for financial funding of this work under a Grantin-Aid for JSPS Fellows.

\section{Authors' contributions}

$\mathrm{AH}$ conducted the experiment of the study and were responsible for data collection and analysis. NF was the supervisor in monitoring the study. Both authors read and approved the final manuscript.

\section{Funding}

This study was funded by the Japan Society for the Promotion of Science (JSPS) under Grant Aid No. 13 F03393.

\section{Availability of data and materials}

The data sets used and analyzed during this study are available from the corresponding author on reasonable request.

\section{Competing interests}

The authors declare that they have no competing interests.

\section{Author details}

${ }^{1}$ Forest Resource Technology, Faculty of Bioengineering and Technology, Universiti Malaysia Kelantan, Kampus Jeli, 17600 Jeli, Kelantan, Malaysia. ${ }^{2}$ Laboratory of Wood Material Technology, Faculty of Agriculture, Kyushu University,

744 Motooka, Nishi-ku, Fukuoka, Japan. 
Received: 6 May 2019 Accepted: 9 October 2019

Published online: 16 October 2019

\section{References}

1. Japanese Agricultural Standard (2007) Standard notification no. 1083 for sawn lumber (in Japanese). Ministry of Agriculture, Forestry and Fisheries, Tokyo, Japan, p 8

2. Ishiguri F, Andoh M, Yokota S, Yoshizawa N (2001) Effect of smoke heating on moisture content, surface checking and dynamic Young's modulus of sugi (Cryptomeria japonica) boxed-heart timber. Mokuzai Gakkaishi 47:350-357 (in Japanese)

3. Kobayashi I, Kuroda N, Hisida T, Takahashi Y (2003) Superheated steam pre-treatment for the drying process of boxed-heart timber from sugi (Cryptomeria japonica D. Don). Wood Ind 58:258-263 (in Japanese)

4. Listyanto T, Ando K, Yamauchi H, Hattori N (2013) Microwave and steam injection drying of $\mathrm{CO}_{2}$ laser incised sugi lumber. J Wood Sci 59:282-289

5. Yoshida T, Hashizume T, Fujimoto N (2000) High-temperature drying characteristic on boxed-heart square timber of karamatsu and sugi-influence of high temperature conditions with low humidity on drying properties. Wood Ind 55:357-362 (in Japanese)

6. Katagiri Y, Fujimoto N, Murase Y (2007) Effect of the treatment temperature on the surface drying set of sugi boxed-heart square timber. Dry Technol 25:507-510

7. Hermawan A, Fujimoto N, Sakagami H (2012) Effects of high-temperature and low-humidity pretreatment on the drying properties of sugi boxedheart timber with black-colored heartwood. Dry Technol 30:780-786

8. Hermawan A, Fujimoto N, Sakagami H (2013) A study of vacuum-drying characteristics of sugi boxed-heart timber. Dry Technol 31:587-594

9. Hisada T (1981) Creep and set behavior of wood related to kiln drying V. Effect of temperature on creep on wood during drying. Mokuzai Gakkaishi 27:381-389 (in Japanese)
10. Fujimoto N, Tachiwana K, Oouchi K, Mataki Y (2001) Tension creep of surface layer and compression creep of inner layer perpendicular to the grain in sugi boxed-heart square timber. J Soc Mater Sci Jpn 50:914-919

11. Moutee M, Fortin Y, Laghdir A (2010) Cantilever experimental setup for rheological parameter identification in relation to wood drying. Wood Sci Technol 44:31-49

12. Hanhijärvi A, Mackenzie-Helnwein P (2003) Computational analysis of quality reduction during drying of lumber due to irrecoverable deformation. I: orthotropic viscoelastic-mechanosorptive-plastic material model for the transverse plane of wood. J Eng Mech 129:996-1005

13. Zhan J, Gu J, Shi SQ (2009) Rheological behavior of larch timber during conventional drying. Dry Technol 27:1041-1050

14. Cai Z, Fridley KJ, Hunt MO, Rosowsky DV (2002) Creep and creep-recovery models for wood under high stress levels. Wood Fiber Sci 34:425-433

15. Hermawan A, Nakahara T, Sakagami H, Fujimoto N, Uchikura K (2013) Performance of sugi lamina impregnated with low-molecular weight phenolic resin. J Wood Sci 59:299-306

16. Cademartori PHG, Schneid E, Gatto DA, Beltrame R, Stangerlin DM (2012) Modification of static bending strength properties of Eucalyptus grandis heat-treated wood. Mater Res 15:922-927

17. Süleyman K, Mehmet B (2009) Effect of high-temperature treatment on the mechanical properties of rowan (Sorbus aucuparia L.) wood. Dry Technol 27:1240-1247

18. Kartal SN, Hwang WJ, Imamura Y (2008) Combined effect of boron compounds and heat treatments on wood properties: chemical and strength properties of wood. J Mater Process Technol 198:234-240

\section{Publisher's Note}

Springer Nature remains neutral with regard to jurisdictional claims in published maps and institutional affiliations.

\section{Submit your manuscript to a SpringerOpen ${ }^{\circ}$ journal and benefit from:}

- Convenient online submission

- Rigorous peer review

- Open access: articles freely available online

- High visibility within the field

Retaining the copyright to your article

Submit your next manuscript at springeropen.com 